\title{
Turning Ideas into Proposals : A Case for Blended Participation During the Participatory Budgeting Trial in Helsinki
}

\section{Ertiö, Titiana-Petra}

Springer

2019-07-26

Ertiö , T-P , Tuominen , P \& Rask , M 2019 , Turning Ideas into Proposals : A Case for Blended Participation During the Participatory Budgeting Trial in Helsinki . in P Panagiotopoulos (ed.), Electronic Participation : ePart 2019 . Lecture Notes in Computer Science, vol. 11686 , Springer, Cham , pp. 15-25, 11th IFIP WG 8.5 International Conference, Italy , 02/09/2019 . https://doi.org/10.1007/978-3-030-27397-2_2

http://hdl.handle.net/10138/317929

https://doi.org/10.1007/978-3-030-27397-2_2

unspecified

acceptedVersion

Downloaded from Helda, University of Helsinki institutional repository.

This is an electronic reprint of the original article.

This reprint may differ from the original in pagination and typographic detail.

Please cite the original version. 


\title{
Turning Ideas into Proposals: A Case for Blended Participation during the Participatory Budgeting Trial in Helsinki
}

\author{
Titiana-Petra Ertiö ${ }^{1}$ [0000-0002-3833-4458], Pekka Tuominen², Mikko Rask ${ }^{1}$ [0000-0002-1065-0192] \\ ${ }^{1}$ University of Helsinki, Faculty of Social Sciences, Centre for Consumer Society Research \\ ${ }^{2}$ University of Helsinki, Faculty of Social Sciences, Media and Communication Studies \\ titiana.ertio@helsinki.fi \\ pekka.tuominen@helsinki.fi \\ mikko.raskehelsinki.fi
}

\begin{abstract}
Balancing between online-offline stages of participatory procedures is a delicate art that may support or hinder the success of participatory democracy. Participatory budgeting (PB), in particular, is generally rooted in online platforms, but as our case study on the City of Helsinki PB trial suggests, face-toface events are necessary to engage targeted and often times less resourceful actors in the process. Based on a longer-term participant observation, covering the PB process from its early to ideation phase to the current stage of proposal development for the final vote, we argue that the process has thus far been successful in blending online-offline components, largely supported by the active support of borough liaisons who have served as navigators between the different stages. From the point of co-creation, different stages of the PB process (ideation, co-creation) call for different strategies of online-offline participation. Effective mobilization of marginalized actors and interactions between public servants and citizens seem to benefit from face-to-face processes, while city-wide voting and discussion can effectively occur in the online platform.
\end{abstract}

Keywords: participatory budgeting, co-creation, technology, civic participation

\section{Introduction: Participatory budgeting, co-creation, and participatory technologies}

Currently, cities seek ways to increase transparency in their operations and service delivery, while at the same time ensure that taxpayer euros are put to work where they are most needed. Whether addressed as civic engagement [1], democratic innovation [2] or hacking the budget [3], participatory budgeting (PB) has reached diffusion in several countries across the globe. PB facilitates structures that enable citizens to propose ideas, develop them into proposals together with public servants, gain support and vote on proposals they consider important for their communities. 
Indeed, the "travel of participatory budgeting" has been intensive. Cabannes and Lipietz [4] identify three phases of PB evolution. The years 1989 to 1997 were a period of experimentation, when the concept was invented in Porto Alegre, and introduced to few other Brazilian cities. In the next phase, variations of PB were generated and it was spread to more than 130 Brazilian municipalities. Since the beginning of 2000s, a phase of expansion and profound diversification followed. In that time, PB travelled throughout Latin America to Europe and North America, and most recently, Asia including China. Overall, more than 3,000 instances of PB across 40 countries have been identified [4].

Diversification of the PB has resulted in different underpinning logics and models. Cabanne and Lipietz [4] distinguish political, technocratic and governance oriented PB. They also refer to the different organizational underpinnings, including territorially, thematically and actor-based models. Sintomer et al. [5] have identified six different PB models - participatory democracy, proximity democracy, participatory modernisation, multi-stakeholder participation, neo-corporatism, community development based on the different contexts, normative frames, procedures, dynamics of collective action, relationships between conventional politics and participatory instruments, as well as strengths, weaknesses and challenges encountered.

Despite such differences, however, there are also commonalities in PB that make it look like a rather coherent tool, perhaps also explaining the attraction of cities worldwide to test and integrate it into municipal planning and decision making. First, PB calls for direct democratic participation of citizens. In particular, PB has proved to be effective in empowering less resourceful citizens and societal groups. Second, PB combines online and offline activities to create effective participatory platforms for the development of new urban ideas and solutions. Unlike some other democratic innovations (e.g. mini-publics), PB has effectively stimulated new technologies and services. Third, PB represents, in many ways, a recent turn of the public sector from a legal authority and service provider to an arena of co-creation, where "co-creation replaces public service monopolies and public-private competition with multi-actor collaboration and in so doing, it transforms the entire perception of the public sector" [6: 4]. Co-creation also facilitates the implementation of those PB proposals that receive most votes, unlike other government crowdsourcing initiatives [7].

The prospect of combining PB and technological innovations includes both design and usage. Holston and colleagues [8: 576-7] performed a review of IT tools that support participatory democracy and citizens' engagement; the authors concluded that none of the solutions they reviewed includes the features needed for instrumenting participatory budgeting online and hence IT solutions are "limited and scattered". The authors developed a prototype called AppCivist-PB that includes a feature themed Citizen Assembly, which enables citizens to organize themselves in small groups and develop PB proposals. Interestingly, the authors emphasized the fact that the feature was inspired by the face-to-face meetings. Similarly, Gilman [1] illustrates a case of PB using a crowdsourced platform called Citizinvestor: residents identified the community need, donated funds to purchase trash cans, and were also involved in their installations. The use of the crowdsourced platform falls under what the author defines as civic tech, "leveraging digital tools to improve democratic governance toward more transparency, 
inclusion, and participatory outcomes" [1: 2]. Thus, online participation on PB platforms translates some of the offline practices like the face-to-face meetings but also gauges which existing tools can be used to the same end as costumed solutions. In contrast, when it comes to the tools and technologies used for civic engagement, Firmstone and Coleman [9] argue that the engagement process is more important than the tools used to reach citizens.

Addressing the issue of digital skills is important to account for the time and effort devoted to develop PB proposals [10]. Much of the PB studies have focused on the deliberative aspects as well as the characteristics of participants' who contributed in PB [2], but their interplay with technology has received less attention. Studies reviewed by Goodwin [2] show that the use of technology indeed increased the number of people who vote on PB proposals as was the case in New York and Vallejo; further, those studies also showed that highly-educated women participated more often and the percentages of Asian voters increased over time [2: 137-138].

Questions related to the choice of online and offline activities, the technology employed and the digital skills needed to participate impact who and how can participate. Evidence is scarce when it comes to PB instruments, but for instance, the study conducted by [11] shows just how complex the phenomena is. The authors did not find any differences in demographics related to gender, income or political orientation but highly educated and non-immigrants participated more often both in online and offline participation activities. Younger, highly educated and non-immigrants were more prevalent online than offline [11]. These results suggest that combining different types of participations across different activities helps public managers to broaden civic engagement.

Stortone \& Cindio [12: 178] identify two problems of online citizen participation. First, the authors argue that the ICTs employed to engage citizens are "top-down", proprietary solutions designed to suit the purposes of the owners. Second, political representatives find it difficult to design effective and appropriate participatory processes regardless of the technology employed. The authors go further to argue that participatory budgeting addresses some of the issues around the advisory nature of citizen involvement, because proposals who receive vast support are actually implemented rather than only having a advisory nature. In a typical participatory budgeting process, citizens both contribute ideas and are involved in the final decisions.

More recently, such concerns have been addressed in the form of open-source software tailored for PB. The Decidim digital platform [13] is a free and open-source platform designed for cities and other organizations that promote participatory democracy. Decidim is particularly scalable to participatory budgeting activities and has been used by several municipalities, including the City of Helsinki. One of the main features of the Decidim platform is organized around the PB stages: idea generation, proposal development, voting - all supported by deliberative features to comment and collaborate online. For the purposes of this paper, we will not detail the entire architecture of the Decidim platform, but rather we are interested in the interplay between the online and offline activities. 
This article responds to Stortone \& Cindio's [12: 179] call to evaluate the impact of participatory budgeting on citizen participation as a whole, both online and offline. We hope to contribute to this call with an elevated understanding of the benefits of blending online and offline engagement as it unfolded in the case of proposal development stage of the Helsinki participatory budgeting trial in 2018-2019. As more cities employ technology to engage the public on the one hand and participatory budgeting on the other, civic managers will find it useful to know how to integrate online and offline activities. Further, we are interested in understanding how the different online and offline aspects of PB contribute to its role as an instrument of co-creation, an important theoretical development that has received less attention than PB's deliberative nature. We formulate our research question as follows: How do online and offline activities blend during the early stages, the ideation stages, and proposal development stages of the PB process, to support meaningful co-creation?

This paper is organized as follows. Section 2 presents the background to the participatory budgeting trial in Helsinki, elaborating also on the methods used to collect the data. Then, in Section 3, we present the results of our study and discuss the findings against our theoretical background. The last section concludes with an argument on hybrid participation to support meaningful co-creation within participatory budgeting processes.

\section{$2 \quad$ Helsinki's participatory budgeting process. Data and methods.}

The City of Helsinki has set a budget of 4.4 million Euros to fund projects proposed by citizens through PB. This budget is divided in a general budget for the entire city plus seven districts that cover the entire municipality; districts' funds are set according to the number of residents. The participatory budgeting process in Helsinki is structured in the following sequential phases: 1) citizens generate ideas, 2) evaluation of ideas proposed against eligibility criteria (see below) by public officials in city departments, 3 ) development of ideas into proposals in co-creation workshops, 4) the city departments estimate the budget for proposals, 5) citizens vote on the proposals they wish to see implemented, and 6) implementation of the proposals. The PB process stresses ample opportunities for discussion and co-creation: among citizens, between citizens, public officials, and other stakeholders, both on the platform as well as face-to-face [14: 24-31].

Establishing a successful balance between online and offline activities results in a complex PB process [12]. This section examines how the online-offline blend is elevated while moving chronologically from the launch of Helsinki PB to its current phase of proposal development. While a considerable part of the PB process depend on the work on the digital platform OmaStadi [15] to document the ideas and proposals, Helsinki's $\mathrm{PB}$ process also emphasizes strongly face-to-face interaction at regular intervals. 
The following analysis is based on a longer-term participant observation of the execution of the participatory budgeting in Helsinki 2018-2019. One of the researchers has conducted ethnographic fieldwork concentrating on the experiences of both participants and organisers of the process since its inception stage in 2017, paying special attention to the shifts in intensities between online and offline environments in the PB different stages. The qualitative data gathered through discussions, observation of different events and participation in a group developing one of the proposals has been supported by the observations of the other researchers, feedback from the participants - as faceto-face discussions, comments on the digital platform as well as comments on the various social media platforms. The authors are researchers in BIBU - Tackling Biases and Bubbles in Participation project that evaluates the Helsinki PB trial.

To start with, in the PB kick-off seminar held in May 2018, the online and offline participation was organised in a blended manner. It was possible to follow the seminar using the Helsinki Channel streaming service and to send comments real-time to a large screen that was centrally located on the stage. The screen was in active use and the topics expressed were frequently raised into the general discussion. However, the seminar was organised in a highly structured manner and some of the participants would have hoped to have the chance for more open-ended discussions.

An important way to facilitate synergies between online and offline activities was the establishment of the borough liaison positions (stadiluotsi, in Finnish). In May 2018, seven borough liaisons were hired by the City of Helsinki to facilitate citizen participation and to provide information about PB. Each of the seven districts of Helsinki (suurpiiri) was assigned their own borough liaison to enable smooth communication between citizens, the city administration, and other partners in the process. Borough liaisons became central actors with several roles in integrating online and offline activities when the local administration began to implement the PB trial.

Since May 2018, the borough liaisons have been very active in meeting citizens both on formal occasions (e.g. neighbourhood association meeting) and during informal face-to-face meetings in public libraries and other easily accessible spaces. A big part of the borough liaisons' time was used in helping the citizens use the OmaStadi platform as some of them were more willing to express their wishes verbally rather than filling in templates using the platform. The borough liaisons' role also extended to their capacity to reply to numerous emails and messages via social media platforms about PB. A significant part of their work took place on their Facebook profiles that were actively used to inform people about the ongoing process. The comment sections contained various questions about the conditions that PB ideas and suggestions have to meet as well as the timetable and the forthcoming events. Many of the people commenting had also met the borough liaisons face-to-face and used social media to continue discussions initiated in the meetings. This provided also a way for the followers to connect with one another while reacting to comments posted on the Facebook profiles. On the other hand, the number of followers of the borough liaisons' Facebook profiles has varied between 400 and 1000, suggesting that this form of digital communication has been a tool used very effectively but has a quite limited reach. 
The ideation stage span from November until mid-December 2018. During the ideation stage of the $\mathrm{PB}$, each of the borough liaisons hosted ideation events in their respective Helsinki region. These events provided personal support for crafting and brainstorming the ideas, meetings with neighbourhood associations and submit them to the OmaStadi platform. In addition, the City of Helsinki printed several brochures and posters to inform the citizens about PB stages and procedures, eligibility criteria, and next steps. In these face-to-face events, the emphasis was on including people who were not active in the online environments to the process. Borough liaisons provided IT support for citizens, specifically helped them sign in on the platform and complete the available template to submit an idea.

The offline aspect of the process was also enriched by a board game specifically designed to support the gathering of the new ideas. The game consists of a set of cards with various tasks and methods to support the ideation process. The logic behind employing the game was to both inform and encourage citizens to engage in a form of direct democracy they were not familiar with. The aim was to create a sociable atmosphere that would turn participants' attention into solving real problems affecting their communities, rather than concentrating on the complex bureaucracy and conditions for proposal acceptance. Borough liaisons organized several sessions that brought together hundreds of Helsinki residents from different backgrounds to sit down and go through the participatory process with its different dimensions over the course of one to two hours. The game was promoted enthusiastically as a new way to bring people together, provide fruitful encounters and extend the reach of participatory budgeting to people not familiar with it. However, some people who already filed ideas found the structure of the game disruptive and would have rather wanted to discuss their ideas in a direct way. The game has also been "given away" to residents and communities so that they can play it on their own. As the game contains instruction for facilitation, it can be played both as coordinated by the borough liaisons as well as regular citizens with their friends, families, or communities. The OmaStadi platform made it possible to support ideas and comment on them but these features were used seldomly. The ideation phase relied on face-to-face events and discussions and the input of ideas on the OmaStadi platform.

After the ideation events with the borough liaisons and the game sessions were over, participants had filled up 1274 ideas on the OmaStadi platform. Of these, 840 were selected by public officials to advance to the next stage as they have met the city's eligibility criteria (e.g. that fall under the municipal jurisdiction). The evaluation of ideas happened online on the OmaStadi platform, with each idea decisioned: either to advance it to the proposal stage or reject it. The rejected ideas received justifications for the decision, so citizens were informed about the specifics as to why their ideas were rejected.

The next phase consisted of PB proposal development (Omastadi raksat) and started in February 2019. Several workshops were organised, one in each municipal district hosted by the respective borough liaison. These workshops were attended by public officials from the city administration, who were invited to provide help to citizens to develop their ideas into proposals. The public officials were invited based on the themes 
present in the ideas submitted (e.g. parks and recreation, leisure services, youth services). The smooth functioning of these workshops was pre-determined by grouping ideas under specific themes; each theme sat at a table. Based on our participant observations at the workshops, there were clear differences depending on the composition of the participants and the facilitation. At times, the vividness of face-to-face interactions during the workshops enabled detailed communication in a group setting and led to effective decision-making that still relied on equal participation. Ideas submitted on the OmaStadi platform were developed either individually or merged with ideas having similar foci and in collaboration with the public officials and fellow participants. Cocreation took a highly practical shape during the proposal development events through the multiple interactions of citizens with public officials, liaisons, and those who commented or supported the ideas online. A separate corner for IT support was set up for the workshops; they drew long queues and frequent mentions about the bugs in the platform and how it is constantly developed to suit the PB project better. These IT support functions were designed to help those who need IT guidance.

We have gathered the data outlined above during our fieldwork on the PB trial. Our methods include participant observation and documentation. Two of the three authors have participated as Helsinki residents in the proposal development workshop in their own borough, in addition to attending other workshops in other boroughs as external evaluators. In the ideation phase, one of the authors has attended the workshops as researcher conducting ethnographic participant observation as mentioned above. In total, we've attended over ten ideation and proposal development events. All of the ten events have been organized and run by the City of Helsinki. In addition to participant observation, another method employed has been that of a case study, specifically an embedded case study [16]. We have followed the entire development of the PB process (case) and studied its different stages and events (several units within the case to use Yin's [16] terminology). Thus, the authors have followed the PB process during a longerterm from understanding the context in which $\mathrm{PB}$ evolved to the very concrete co-creation actions in the proposal development stage.

\section{Results and discussion: Blending online and offline co- creation activities in Helsinki's PB trial}

This section structures our observations from the field about blending online-offline activities in the Helsinki PB to support co-creation activities and discusses their implications against the theoretical framing outlined in the beginning of the article.

The Helsinki PB process described in this article reviews Helsinki's first major PB trial. As a trial, the efforts to increase awareness and organize events, inform residents of the opportunity to participate, about the technicalities of the project have been extensive. In considering PB as a democratic innovation, the trial introduced new ways of soliciting ideas and co-creating them with residents as well as establishing ways to respond to citizens' ideas inside the city administration. 
Following the PB process stages, particularly ideation and proposal development, online and offline activities blended concurrently. Each event sought to increase understanding of the PB process and lead to active participation on the OmaStadi platform. In the kick-off seminar, the questions sent via online tools supported and spurred the discussion present in the room. Ideas were formally submitted on the platform but the pre-stage - when citizens ideated what to submit - took sometimes place offline, for instance by playing the participation game. Ideas have been somewhat commented and supported on the OmaStadi platform, but discussions took mainly place offline in the events organized. In the development stage, the online-offline integration was most visible as citizens co-created their ideas with public officials after which they submitted their proposals on the OmaStadi platform. Further, the presence of IT support in the proposal development workshops facilitated capacity building for those less experienced with online tools. For certain demographics, the existence of IT support can be considered critical to their participation in PB. In contrast, idea selection - choosing ideas to be developed into proposals - took place entirely on the OmaStadi platform.

On an institutional level, creating roles that further the integration of online and offline activities and facilitate co-creation processes was vital to support citizens in the PB trial. Borough liaisons represented a new position created within the city administration to support the nascent PB ecosystem formed of citizens, public officials, nongovernmental organizations, communities, and groups. Much of the liaison's work consists of fieldwork and answering citizen queries online about the PB. Similarly, they guide and support citizens to submit and develop their ideas. Essentially, they act as facilitators and intermediaries between the city administration and citizens.

In this article, the focus is on the early stages of the PB process which, we argue, is critical for co-creation. It sets out the ideas, opportunities, and proposals that citizens initiate and co-create with the other actors involved in PB. Our results show that online and offline activities are seamlessly integrated but not in equal proportions in the PB process. There are PB stages at which both online and offline activities are blended such as ideation and proposal development. We find that offline, face-to-face events and workshops are meant to support the input of ideas and proposals on the OmaStadi platforms. While [8] detail how features on the online platform takes inspiration from face-to-face meetings, the Helsinki PB shows how the two can be integrated concurrently. All the documentation on the PB proposals is formally submitted via the platform OmaStadi platform. The IT support by the borough liaisons integrates the onlineoffline activities. However, the selection of ideas took place online. To sum up, we find that face-to-face meetings support the use of the platform, making the PB process also facilitate IT capacity building in addition to the democratic inclusion. This lets us appreciate the benefits of blended activities for PB as proposed by [1,12]. For this article, we have no quantitative data to detail the characteristics of the demographics who participated in PB; we recognize that this is a substantial limitation of our study. We intent to investigate the effect of the IT support provided for marginalized groups to develop the IT skills to be able to assess the digital equity of PB. 
Following [6], we observe that in the PB trial in practice, co-creative engagements are unequally organised. As mentioned, ideation and proposal development heavily rely on co-creation activities. Whether it is the participation game that help to ideate together or an idea a citizen had that received support and comments online and offline, the ideation stage opens the co-creation process. When ideas are decisioned, this is mainly the duty of public officials in city departments. Proposal development, on the other hand, makes co-creation between idea proponents and public officials an essential component to enrich citizens' proposals. The results highlight how co-creation developed in the specific instance of the Helsinki PB stages, contributing to a deeper understanding of the variation, national context, and different phases of the process [17].

"Participatory budgeting is not [...] a time-saving institution. It is resource intensive. Its civic appeal lies precisely in the deliberative process and the information ecosystem it creates" notes Hollie Gilman [10:3]. Indeed appreciating the online and offline activities in PB [1,12] on the one hand, and "transform[ing] the entire perception of the public sector" through co-creation [6:4] on the other hand, requires particular attention to detail in facilitating social innovations, ideals of democratic governance, including transparency and inclusion.

Given that the PB case presented in this article is a trial, it has required considerable effort to create awareness about the opportunity it represents for citizens. Getting the PB process - like any participatory method - off the ground necessitates effort to get acquainted with the PB (for citizens) as well as managing the process (within the city administration and in terms of stakeholder management). The next PB round is expected to build and expand on the lessons learned in this trial. We anticipate that citizens' awareness will increase with each PB round and the efforts will shift towards other stages. As the PB trial progresses, one area of future research we will develop will be to determine who participated, assessing whether offline and online participants were the same and the effect of the alternating online-offline activities had on different demographic groups during the PB trial.

\section{Conclusions}

Participatory budgeting facilitates structures that enable citizens to propose ideas, develop them into proposals together with public servants, gain support and vote on proposals they consider important for their communities. Lately, dedicated technologies sustain participatory budgeting efforts, such as the Decidim platform. This article has reviewed the case of the Helsinki participatory budgeting trial, illustrating how onlineoffline activities have supported co-creation activities in the Helsinki. We found that online and offline activities are integrated seamlessly during the early stages of the process and that co-creation activities tend to aggregate in the ideation and proposal development phases that coincide with face-to-face events. Offline activities support the creation and development of formal submissions on the OmaStadi platform. Central to 
supporting these activities are borough liaisons, who support the PB process online and offline.

The results of this analysis will contribute to a better understanding of "deliberative systems" [18] and participatory ecosystems more generally. As some studies have suggested [19], the field of public participation has recently encountered a shift from a focus on individual participatory events to a focus on more systemic and institutional considerations. Core issues are how to connect formal institutions with informal networks and civil society, in a meaningful way, thus engaging different discourses with each other. As our analysis has suggested, adding new types of intermediaries, such as borough liaisons, can help in such development, by using participatory technologies combined with direct communication with the citizens involved.

Yet another important contribution of this line of research is gaining more detailed understanding of the factors contributing to more inclusive and equal strategies in designing and implementing participatory processes. Previous studies have paid attention on factors such as framing of the issues, marketing of the events, differences in citizen recruitment strategies and socio-demographic variables [see e.g. 11,20]. This paper has raised the issue that the right balance between online-offline participation can also contribute to better involvement strategies. Our limited data did not allow drawing exact conclusions on this matter, but we observe that future studies should pay more close attention on this aspect of participatory democracy innovations.

Acknowledgements: This study has received funding from the Strategic Research Council at the Academy of Finland (consortium decision number 312710, BIBUTackling Biases and Bubbles in Participation, sub-project number 312796). The authors would like to thank the three anonymous reviewers for their comments, that have greatly developed this study.

\section{$5 \quad$ References}

1. Gilman, H.: Participatory Budgeting and Civic Tech: The revival of Citizen Engagement. Washington, DC, Georgetown University Press (2016).

2. Godwin, M.: Studying Participatory Budgeting: Democratic Innovation or Budgeting Tool? State and Local Government Review 50, 132-144 (2018). https://doi.org/10.1177/0160323X18784333

3. Schuler, D.: A Hacking atlas: holistic hacking in the urban theater. In De Lange, M. \& de Waal, M. (eds.) The Hackable City. Digital Media and Collaborative City-Making in the Network Society. pp. 261-282. Springer, Singapore (2019). https://doi.org/10.1007/978981-13-2694-3

4. Cabannes, Y., \& Lipietz, B.: Revisiting the democratic promise of participatory budgeting in light of competing political, good governance and technocratic logics. Environment and Urbanization, 30, 67-84. (2018). doi: 10.1177/0956247817746279

5. Sintomer, Y., Röcke, A., Herzberg, C.: Participatory Budgeting in Europe: Democracy and Public Governance. Routledge, New York (2016) 
6. Torfing, J., Sørensen, E., Røiseland, A.: Transforming the public sector into an arena for cocreation: barriers, drivers, benefits, and ways forward. Administration \& Society, 1-31 (2016). doi: 10.1177/0095399716680057

7. Liu, H. K.: Crowdsourcing government: Lessons from multiple disciplines. Public Administration Review, 77, 656-667 (2017). https://doi.org/10.1111/puar.12808

8. Holston, J, Issarny, V., Parra, C.: Engineering software assemblies for participatory democracy: the participatory budgeting use case. ACM IEEE International Conference on Software Engineering Companion, pp. 573-582. (2016). doi: 10.1145/2889160.2889221

9. Firmstone, J., Coleman, S.: Public engagement in local government: The voice and influence of citizens in online communicative spaces. Information, Communication \& Society, 18, 680-695 (2015). https://doi.org/10.1080/1369118X.2014.986180

10. Gilman, H.: Democracy Reinvented: Participatory Budgeting and Civic Innovation in America. Washington, DC, Brookings Institution Press (with Ash Center for Democratic Governance and Innovation, Harvard) (2016).

11. Pina, V., Torres, L., Royo, S.: Comparing online with offline citizen engagement for climate change: Findings from Austria, Germany and Spain. Government Information Quarterly, 34, 26-36 (2017). http://dx.doi.org/10.1016/j.giq.2016.08.009

12. Stortone, S., De Cindio, F.: Hybrid participatory budgeting: Local democratic practices in the digital era. In Foth, M., Brynskov, M., Ojala, T. (eds.) Citizen's right to the digital city. pp. 177-197. Springer, Singapore (2015).

13. Decidim platform Homepage, https://decidim.org/, last accessed 2019/3/16.

14. Helsinki participatory model, https://www.hel.fi/static/liitteet/kanslia/asukasyhteistyo/osallisuusmalli-yleisesitys-2018.pdf , last accessed 2019/3/16.

15. OmaStadi platform Homepage, https://omastadi.hel.fi/ , last accessed 2019/3/16.

16. Yin, R.K.: Case Study Research: Design and Methods. (5th ed.). Thousand Oaks, CA, Sage (2013).

17. Nabatchi, T., Steen, T., Sicilia, M., Brand, D.: Understanding the diversity of coproduction: Introduction to the IJPA special issue. International Journal of Public Administration, 39, 1001-1005 (2016). https://doi.org/10.1080/01900692.2016.1177836

18. Dryzek, J. S., Niemeyer, S.: Deliberative democracy and climate governance. Nature human behaviour, 3, 411-413 (2019). DOI: 10.1038/s41562-019-0591-9

19. Rask, M., Worthington, R.: Communicating about biodiversity, public engagement, and climate change. Oxford research encyclopedia of climate science. Oxford, UK: Oxford University Press (2017). DOI: 10.1093/acrefore/9780190228620.013.420

20. Goldschmidt, R., Tomblin, D., Rask, M.: The role of gender in global citizen deliberation. In Rask, M., Worthington, R. (eds.) Governing biodiversity through democratic deliberation. pp 130-151. Routledge, London and New York (2015). 